\title{
Hypersensitivity pneumonitis associated with temozolomide
}

\section{To the Editors:}

In the March 2009 edition of the European Respiratory Journal, Koschel et al. [1] reported the case of a 54-yr-old female presenting with pneumonia associated with the use of temozolomide and whose clinical and radiographic presentation and anatomo-pathological signs were consistent with hypersensitivity pneumonitis. During the phase II trials preceding the marketing of this alkylating agent, which is a derivative of dacarbazine, interstitial pneumonias were described, but with no details of their mechanism [2, 3]. A case of temozolomide-associated organising pneumonitis has also been published [4].

The observation by Koschel et al. [1] is very similar to the one published by our group in the Revue des Maladies Respiratoires in September 2008 [5], in which we also described a case of pneumonitis consistant with the hypersensitivity mechanism, but without the anatomo-pathological evidence obtained by Koschel et al. [1] in their case. It concerned a 56-yr-old patient admitted in January 2007 with a bifocal glioblastoma. The patient underwent whole brain radiotherapy combined with $120 \mathrm{mg}$ temozolomide per day from February 12 to March 26, 2007. From May 3, 2007, a 225-mg dose of temozolomide was administered daily for 5 days per month as maintenance treatment. A few days after the first maintenance cycle, the patient developed a stage II dyspnoea, with $38.5^{\circ} \mathrm{C}$ fever spikes. Chest radiographs showed a predominantly left-sided interstitial syndrome. A bilateral interstitial syndrome combined with discrete pulmonary condensation was documented with thoracic computed tomography. Bronchoalveolar lavage revealed an alveolitis with $70 \%$ lymphocytes. The severity of respiratory symptoms made it impossible to carry out a lung biopsy. In contrast to the case reported by Koschel et al. [1], the alveolar lavage found no micro-organism to suggest an infectious cause, and the patient was receiving no treatment apart from the temozolomide. Faced with the imputability of temozolomide, the treatment was therefore stopped and corticotherapy was increased from 20 to $60 \mathrm{mg}$ per day of prednisone equivalent. The clinical respiratory improvement was rapid. The chest radiograph returned to normal within 1 month.
French pharmacovigilance centres have reported five cases of interstitial radiological syndrome associated with the use of temozolomide, of which only one underwent a bronchoalveolar lavage revealing lymphocytosis, and no case was the subject of an anatomopathological study prior to the one reported by Koschel et al. [1]. These observations as a whole are thus entirely consistent with the hypothesis put forward by Koschel et al. [1] that pneumonia associated with the use of temozolomide is linked with hypersensitivity to the drug, and it is therefore important to specify this possible side-effect in the summary of the product's characteristics.

\section{Guilleminault, P. Carré and P. Diot}

Centre Hospitalier Universitaire de Tours, Tours, France.

Correspondence: L. Guilleminault, Centre Hospitalier Universitaire de Tours, 2 Boulevard Tonnellé, 37044 Tours, France. E-mail: guillel@free.fr

Statement of Interest: None declared.

\section{REFERENCES}

1 Koschel D, Handzhiev S, Leucht V, et al. Hypersensitivity pneumonitis associated with the use of temozolomide. Eur Respir J 2009; 33: 931-934.

2 Abrey LE, Olson JD, Raizer JJ, et al. A phase II trial of temozolomide for patients with recurrent or progressive brain metastases. J Neurooncol 2001; 53: 259-265.

3 Chinot $\mathrm{O}$, Barrié $\mathrm{M}$, Cournède $\mathrm{A}$, et al. Phase II study of temozolomide (TMZ) administered on a 7 days on, 7 days off regimen as primary treatment before radiotherapy (RT) in inoperable newly diagnosed glioblastome multiforme (GBM). J Clin Oncol 2005; 23: Suppl. 16, 1523.

4 Maldonado F, Limper AH, Lim KG, et al. Temozolomide-associated organizing pneumonitis. Mayo Clinic Proceedings 2007; 82: 771-773.

5 Guilleminault L, Carré P, de Luca K, et al. Alveolo-interstitial pneumonia due to Temozolamide. Rev Mal Respir 2008; 25: 880-884. 